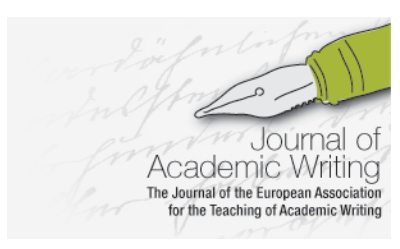

Journal of Academic Writing Vol. 10 No 1 WINTER 2020, pages 188-194 https://doi.org/10.18552/joaw.v10i1.630

\title{
Preparing Postgraduates for the Profession: Toward Translingual Pedagogical Practices in Advanced Graduate Student Writing Instruction in Germany
}

\author{
Micha Gerrit Philipp Edlich \\ Leuphana University Lüneburg, Germany
}

\begin{abstract}
Contributing to the literature on translingual pedagogies outside the US or Canada, this article discusses the design of a hybrid instructional format for advanced multilingual doctoral students and post-doctoral researchers offered by a bilingual writing center at a mid-sized university in Germany. Meant to prepare participants for future careers in academia and professional demands in different national, cultural, and linguistic environments, this format provides the opportunity to explore academic genres that tend to receive less attention in graduate education than journal articles, book chapters, or genres needed to complete degree requirements. By the end of the course, participants will have a submission-ready portfolio including an academic $\mathrm{CV}$, a job letter, a (sample) letter of recommendation, and teaching and diversity statements. To achieve these specific outcomes and to develop the advanced professional academic writing competencies needed in multicultural and multilingual contexts, participants will have to draw on their diverse linguistic backgrounds and prior experiences in these kinds of settings. Informed also by other recent theoretical and empirical work on translingualism and translingual pedagogies in global contexts, this format adopts the use of translation proposed by Horner (2017) to move beyond the monolingual and, to a lesser extent, multilingual paradigms. While it has yet to be tested empirically, the design represents an alternative to more traditional (and usually monolingual) modes of instruction. This article concludes by discussing limitations and implications of the approach to translingual pedagogies taken here.
\end{abstract}

\section{Introduction}

Among other dramatic changes, globalization in higher education in general and individual internationalization initiatives at universities worldwide have led to a shift in writing studies pedagogy and research (Conference on College Composition and Communication, 2017). These global institutional, administrative, and pedagogical developments have focused on increasing the visibility and importance of multilingual writers and have been addressed in a recent spate of theoretical and empirical studies on, to give but two research lines, transnational writing program administration (Martins, 2015) and innovative translingual pedagogical practices in writing programs and at writing centers worldwide (e.g. Bou Ayash, 2019; Brinkschulte et al., 2018; Horner \& Tetreault, 2017). The emerging discourse on translingual pedagogical practices, especially in contexts outside the US or Canada, has been preceded and informed by larger, often overlapping theoretical debates in composition and rhetoric and other fields such as applied linguistics (Canagarajah, 2013, p. 9).

For example, applied linguists have proposed terms such as translanguaging (Canagarajah, 2013 , p. 9) to theorize linguistic developments, practices, and pedagogies resulting from "the global flows of people and things" (Appadurai 1996, p. 29). In composition and rhetoric, theoretical as well as practical attempts to think, conduct research, and teach beyond what has 
been referred to as the monolingual and multilingual paradigms have often been discussed under the banner of translingualism (Canagarajah, 2013; Horner et al., 2011; Horner \& Tetreault, 2017; Horner \& Alvarez, 2019). In this context, the boundaries between translingualism and multilingualism, at both the theoretical and practical level, are very much subject to debate (e.g. Bou Ayash, 2019, p. 25; Guerra \& Shivers-McNair, 2017). However, researchers and practitioners seem to agree that translingualism needs a clear definition, specific theoretical assumptions, and related teaching practices for writing programs and centers worldwide to be able to fully commit to interrogating power structures inextricably linked to monolingualism. Through this grounding, translingualism, ideally informed by "core tenets" (Lavelle, 2017, p. 198), can become a guiding principle of scholarly inquiry and pedagogy. It can also remind scholars not to take for granted assumptions about language, especially when writing in today's complex multilingual contexts.

This article contributes to the debate about the practical implications of translingualism and, more specifically, to the growing body of literature on translingual pedagogical practices by discussing the design of a hybrid instructional format for advanced multilingual doctoral students and post-doctoral researchers with different disciplinary backgrounds. Offered by an officially bilingual writing center, the Schreibzentrum / Writing Center at Leuphana University Lüneburg, a mid-sized university in Germany, this instructional format aims to complement other curricular and non-curricular offers for personal and professional development in and outside of academia delivered by Leuphana's Graduate School. The format focuses on genres such as academic CVs, job letters, letters of recommendation, and teaching and diversity statements. These genres are often key to professionalization, but they seem to receive little attention in structured doctoral programs in Germany today. Completing the course with a submission-ready portfolio, participants ideally will develop, among other educational goals, their ability to work with these genres across linguistic, cultural, national, or disciplinary boundaries. Both the general design of this format and one of the key methods to achieve these educational goals are based on Horner's (2017) argument for mixed-language writing and especially translation and double translation as translingual pedagogical practices.

Choosing this approach to teaching professional academic genres may seem counterintuitive at first, impossible at worst. If anything, genres such as job letters are, due to their gatekeeping function (for both faculty and students), closely linked to power structures in higher education (and beyond) that reflect and are maintained by monolingualism. Monolingual mastery of genres such as applications might turn out to be the competitive edge that early career researchers need to succeed in a crowded and increasingly global market. Given the high stakes, a hybrid instructional format such as the one discussed here must acknowledge these realities in its outcomes. Yet such challenges can be addressed by juxtaposing analyses of models and emulations of the presumed standard or norm with instructional methods such as translation and double translation. The methods proposed by Horner (2017) could help some multilingual students to develop a sense of agency, linguistic or otherwise, at a stage when their future career trajectory may seem beyond their control. The hybrid format also aims to foster a "disposition to openness and inquiry" (Horner et al., 2011, p. 311). From an institutional perspective, offering this course could also be a means to achieving another important goal identified in many theoretical studies on translingualism, namely, an opportunity to interrogate often unarticulated (monolingual) assumptions concerning language, writing, pedagogy, and the experiences of multilingual writers.

The remainder of this contribution is structured as follows: The first short section briefly addresses the institutional context at Leuphana's Schreibzentrum / Writing Center, which determines the conditions and related pedagogical principles. The second section relates some of these principles to the theoretical framework for the course by discussing the distinct advantages of Horner's (2017) intervention. The third section provides a general overview of the course design and sequences, with the fourth addressing potential challenges and implications. The last section concludes with a brief summary and outlook. 


\section{Context}

The course discussed here was developed by staff members at the bilingual Schreibzentrum I Writing Center at Leuphana University, a mid-sized university in northern Germany, which is the result of a merger of two essentially monolingual writing centers (one focused on German, one on English) into one organizational unit in 2016. This significant structural change, an attempt by the university administration to, among other aspects, increase the visibility of the writing center and to reduce administrative overhead, was accompanied by a subsequent reconceptualization of its mission and a stronger emphasis on Mehrsprachigkeit, or multilingualism. This reorientation was partly a response to the university's internationalization initiatives, a readjustment necessary to an increasingly diverse student population, and the unexpected result of hiring decisions. The last factor in particular, that is, the distinct constellation of staff members who differ considerably in terms of their educational background, focus areas, research and scholarly interests, and personal experience, has continued to influence the writing center's institutional and pedagogical evolution. Although the outcome of all of these processes is not unique in German higher education - a similar context and development can be observed at the International Writing Centre at Göttingen University (Brinkschulte, Grieshammer, \& Stoian, 2018) - it seems that even top-down institutional change can be an opportunity to prepare the ground for a turn toward Mehrsprachigkeit and translingualism.

The shift toward Mehrsprachigkeit at Leuphana's Schreibzentrum / Writing Center can also be explained by the scholarly interests and research agendas of staff members. The two permanent staff members have drawn on individual and co-authored studies by Canagarajah (e.g. Canagarajah \& Jersky, 2009; Canagarajah, 2013). They have also explored the differences and similarities between, on the one hand, German language literature on Mehrsprachigkeit and writing center work in continental Europe and, on the other hand, literature on North American writing programs and writing centers, multilingualism, and translingualism, especially in composition and rhetoric in the US. One consequence of these ongoing internal explorations is that the institutional and research objectives continue to evolve. In this context, theoretical work on translingualism functions as a benchmark and a check on administrative and pedagogical practices. In the case of the course discussed here, the publication of Horner and Tetrault's award-winning collection Crossing Divides: Exploring Translingual Writing Pedagogies and Programs (2017), and Horner's contribution "Teaching Translingual Agency in Iteration: Rewriting Difference" in particular, gave the impetus to reconsider how genres such as academic job letters or CVs could or should be taught in multilingual contexts.

\section{Theoretical framework}

Horner's (2017) contribution discusses three key practices - mixed-language writing, translation, and double translation - as unexpected yet potentially effective translingual pedagogical practices. Introducing these practices in the composition and rhetoric classroom allows students, Horner (2017, p. 92) argues, to "ask what differences specific language practices-whether seemingly conventional or not-might make to the positioning or writers and readers and to contexts, knowledge, language, and the relation of all these to one another." In the case of using double translation, which he defines as "translating words and phrases identifiable as English into language marked as not English and then back" (Horner, 2017, p. 92), the goal is not to find a translation that accurately conveys the meaning of the original. Doing so, as Horner (2017) also cautions, could result in reintroducing monolingual ideology into the classroom. Instead, students rather seek to find more than translation and to consider the differences that emerge when engaging with language practices in this manner.

Horner's (2017) translingual intervention might raise a few questions, for example, concerning its applicability in some classroom settings or its focus in words and phrases. However, this article argues that it can open up new perspectives for advanced multilingual students (and instructors alike), especially if translation becomes nearly impossible due to considerable 
linguistic, cultural, or disciplinary differences, as in the case of professionalization documents. As Horner et al. (2011, p. 284) note in a different context (i.e., an argument calling for translingual research on writing), "any translation is an act of rewriting, necessarily provisional and productive of different meanings." Being confronted with these different meanings across multiple divides (Horner and Tetreault's 2017 term) and the ways in which these are constructed or manipulated, students can, as suggested in the following section, interrogate and begin to appropriate dominant monolingual discourses. They may also develop a sense of agency and the ability to successfully negotiate multiple cultural, national, linguistic, and disciplinary borders.

\section{Course design and instructional methods}

Many advanced doctoral students and post-doctoral researchers at Leuphana University have a considerable teaching load and, in many cases, also administrative functions. To accommodate these conditions, the proposed course design involves five two-hour sessions with the entire group. These sessions, each of them focused on one of the genres, are scheduled in the periods between teaching terms. These sessions are complemented with one or more small-group workshops (with or without the instructor, depending on the needs or expectations of participants) or peer review involving at least two participants. The schedule also includes periods in which participants have the option of working with the instructor or other staff members at the writing center. Sessions and workshops focus on macro issues and provide opportunities to engage in and with the three key translingual practices adopted from Horner (2017) - mixed-language writing, translation, or double translation. Consultations (in person or online), especially toward the end of the course, deal with grammatical, stylistic, and formal issues, and increasingly emphasize monolingual norms and culturally specific genre conventions.

Participants are encouraged to engage in the three key practices at any time for the first drafts of documents. These practices are briefly introduced in the first session along with the general approach taken in this course. There are no restrictions on the number of languages, although it is safe to assume that most of the multilingual participants, usually native speakers of German with either B2 or C1 English language skills, can expend only some of their limited time on these practices or the course in general. They can use a draft or final version of a document in a language other than English as a starting point or start from scratch, either using English, any other language(s), or both at the same time. Participants can also opt to use an adaptation of the sequence proposed by Lange (2015). For example, they can create an outline in their favorite language and then turn it into the first draft using another one, or they may write a text in different languages and then turn this mixed-language draft into an English one during revision.

The format not only relies on the three key practices for creating early drafts of professional documents, but also gives participants an opportunity to explore cultural and linguistic differences between, for example, composing a letter of recommendation across US and German contexts. It is important to note here that the German language literature on this and other professional genres is scant, which results in its own distinct set of challenges for professionalization efforts. If available, anonymized authentic texts shared by faculty with permission of students (for example in the case of letters of recommendation) or publicly available documents (such as academic CVs posted on personal websites) can serve as models during group sessions. In contrast, this kind of genre knowledge is readily available in the English language literature. For example, teaching guides such as Anne Curzan and Lisa Damour's First Day to Final Grade (2000, p. 191-93) include sample letters, which can easily be adopted by graduate student instructors. These models, which might also be used in monolingual approaches to teaching professionalization documents, could be juxtaposed with German texts to illustrate differences between, for example, a letter of recommendation written in a US context and one in a German context.

In this course, the practices proposed by Horner (2017) are meant to create an opening to interrogate these differences. For example, a German translation of an English draft letter by a 
doctoral student educated in the US is likely to raise a few eyebrows during a workshop including participants whose first language is German and who have been socialized in the German academy. This letter, even if it is grammatically correct and meets many expectations of the addressee, may differ from those written in a German context in terms of, among other aspects, length, level of detail, tone, and connotations of standardized phrases (especially those used in concluding paragraphs). This text, even if it is translated into English again, would strike participants unfamiliar with conventions in the United States as too enthusiastic or too personal. Ideally, engaging with professionalization documents in this manner might also lead to other questions among participants. To what extent, for example, do they need to appropriate and approximate the monolingual norm if they are not based in the Anglo-American academy, but addressing members of that community? Unable to fully determine whether the document they submit is precisely what readers are looking for, participants still need to choose how and to what extent they conform to monolingual norms.

While it is impossible to answer such questions conclusively, discussions of these subtle linguistic and cultural differences can deepen participants' genre knowledge and reframe professionalization documents from a global perspective. As they draft, compare, revise, and respond to letters of recommendation and other professional academic genres, participants need to make informed decisions regarding differences across multiple borders. Facing numerous unknowns, participants might nonetheless develop a sense of agency. To make sure they can do so in a productive environment, participants are expected to treat all documents and related information, particularly concerning applications for positions, as confidential, to use them only for the expressed purpose of the course, and to avoid conflicts of interest.

\section{Challenges}

The approach to teaching advanced doctoral students and post-doctoral researchers proposed here has two potential limitations. First, although adopting the three key practices proposed by Horner (2017) seems to be a promising means to achieve educational goals, such as the ability to work in and with professional genres, neither the instructor nor the participants are trained or certified translators. The related lack of theoretical and methodological knowledge and experience, which could be addressed in another institutional context by collaborating with faculty with a background in translation studies or at least adding resources on translation, is likely to pose a challenge for most participants. In very practical terms, this may require participants to reallocate limited resources that they might rather use on their research projects.

However, as noted above, committing to this approach can open up a space for exploring the parts of professionalization documents where mere literal translations, even if they are grammatically correct and seem stylistically appropriate for intended audiences, prove inadequate because they fail to consider crucial cultural and national differences. A better understanding of the knowledges and expectations of search committees, administrators, or various literacy brokers (Lillis \& Curry, 2010) can be beneficial here. Similarly, understanding linguistic difference not in terms of monolingual norms, but rather as factors to consider when negotiating differences in writing, can provide an opportunity for participants to develop a sense of agency, one that is needed in different dynamic professional environments. The final products of these processes may differ from professionalization documents written by native speakers, in part because participants may not be entirely familiar with very specific disciplinary norms. In these kinds of cases, departures from the norm, intentional or not, admittedly pose a considerable risk, albeit one also faced by native speakers whose incomplete appropriations may likewise be deemed inauthentic.

Whether the tension between the pedagogical approach proposed here and the valorization of monolingual professional documents can ultimately be resolved remains to be seen. It is possible that for many doctoral candidates and post-doctoral researchers eager to pursue academic careers, a ready-made, highly polished application may, at the time, be of greater value than acquiring the competencies needed to prepare the related professionalization documents. There is, then, potential for a conflict between the instructor asking participants to explore translingual practices and participants who signed up for the course to fast track their 
entry into the academic job market. Moreover, the outcome of the course, the portfolio, may eventually be free of decisions concerning languages and of traces of the complex processes that have come beforehand. Indeed, the translingual pedagogical practices employed during the process will eventually be hidden behind final products that, at least in appearance, seem to affirm monolingualism and related power structures. This trajectory will be particularly obvious during consultation, in which issues such as standard varieties, usage, or style are commonly raised by students regardless of their level, experience, or goals. One might argue, then, that while the course integrates practices pointing toward a translingual pedagogy, the design rather must be understood as multilingual gesturing toward the translingual.

\section{Conclusion and Outlook}

Despite the two main challenges discussed in the previous section, the general design proposed here, which adapts Horner's (2017) intervention to the context of teaching advanced doctoral and post-doctoral multilingual writers how to compose, evaluate, and revise professionalization documents, might be of interest to staff in writing programs or centers. The design might be especially useful for those who seek to move beyond the monolingual paradigm and, by encouraging students to draw on all of their linguistic resources, aim to provide them with a sense of agency in academia and beyond. While mixed-language writing, translation, and double translation could certainly be developed by, as suggested above, collaborating with translators or faculty in translation studies, Horner's (2017) proposal might also be adapted to a wide range of other contexts, for example to more common academic genres in disciplines in which English is not (yet) the lingua franca, but is increasingly important, as well as to contexts in which early career researchers need to demonstrate a publication record in more than one language.

Although it has yet to be empirically tested, the design of a hybrid instructional format for advanced multilingual doctoral students and post-doctoral researchers discussed here may offer an alternative to traditional approaches to teaching professionalization documents such as job letters, CVs, or letters of recommendation. Adopting Horner's (2017) proposal for the potentially translingual practices of mixed-language writing, translation, and double translation, this format seeks to move beyond the monolingual paradigm and to gesture toward a translingual one, so as to help participants develop the agency and ability to negotiate linguistic and cultural differences in a global environment. Introducing this kind of format in graduate and postgraduate writing programs is, however, likely to be only a tentative first step in that direction. After all, as Lavelle (2017) points out, "seepage" (p. 194) of "essentializing linguistic ideologies" (p. 195) is a constant problem. It remains to be seen whether this approach to developing multilingual doctoral students and post-doctoral researchers could be an option for writing program and writing center staff members hoping to leverage diverse linguistic backgrounds. Evaluations and long-term empirical research on this design may provide some guidance in this respect. Implementing, testing, and improving this specific design in various institutional contexts can be understood as a practical response to Horner's (2017) proposal to develop and assess the potential translingual pedagogical intervention in multilingual contexts. As this article suggests, doing so would be, in line with the recent theoretical and empirical literature on translingualism, one means to make sure that writing programs, writing centers, and students continue to interrogate the ways in which they use language and negotiate cultural, disciplinary, and institutional norms.

\section{Acknowledgments}

I would like to thank the editors and the anonymous reviewers for their thoughtful feedback on earlier versions of this article. 


\section{References}

Appadurai, A. (1996). Modernity at large: Cultural dimensions of globalization. University of Minnesota Press.

Bou Ayash, N. (2019). Toward translingual realities in composition: (Re)Working local language representations and practices. Utah State University Press.

Brinkschulte, M., Grieshammer, E., \& Stoian, M. E. (2018). Translingual academic writing at internationalised universities: Learning from scholars. Journal of Academic Writing, 8(2), 150-160. https://doi.org/10.18552/joaw.v8i2.460

Canagarajah, S. (2013). Translingual practice: Global Englishes and cosmopolitan relations. Routledge.

Canagarajah, S., \& Jerskey, M. (2009). Meeting the needs of advanced multilingual writers. In R. Beard, D. Myhill, J. Riley, \& M. Nystrand (Eds.), The SAGE Handbook of Writing Development (pp. 472-488). SAGE.

Conference on College Composition and Communication (2017). CCCC statement on globalization in writing studies pedagogy and research. https://cccc.ncte.org/cccc/resources/positions/globalization

Curzan, A., \& Damour, L. (2000). First day to final grade: A graduate student guide to teaching. University of Michigan Press.

Guerra, J. C., \& Shivers-McNair, A. (2017). Toward a new vocabulary of motive: Re(con)figuring entanglement in a translingual world. In B. Horner \& L. Tetreault (Eds.), Crossing divides: Exploring translingual writing pedagogies and programs (pp. 19-30). Utah State University Press.

Horner, B. (2017). Teaching translingual agency in iteration: Rewriting difference. In B. Horner \& L. Tetreault (Eds.), Crossing divides: Exploring translingual writing pedagogies and programs (pp. 87-97). Utah State University Press.

Horner, B., \& Alvarez, S. B. (2019). Defining translinguality. LiCS, 7(2), 1-30. https://licsjournal.org/index.php/LiCS/article/view/221

Horner, B., Lu, M.-Z., Royster, J. J., \& Trimbur, J. (2011). Language difference in writing: Toward a translingual approach. College English, 73(3), 303-321. https://www.jstor.org/stable/25790477

Horner, B., NeCamp, S., Donahue, C. (2011). Toward a multilingual composition scholarship: From English only to a translingual norm. College Composition and Communication, 63(2), 269-300. https://www.jstor.org/stable/23131585

Horner, B., \& Tetreault, L. (Eds.) (2017). Crossing divides: Exploring translingual writing pedagogies and programs. Utah State University Press.

Lange, U. (2015). Mehrsprachige Wege zu einsprachigen Texten. ide, 39(4), 133-141.

Lavelle, T. (2017). The ins and outs of translingual work. In B. Horner \& L. Tetreault, L. (Eds.), Crossing divides: Exploring translingual writing pedagogies and programs (pp. 19098). Utah State University Press.

Lillis, T., \& Curry, M. J. (2010). Academic writing in a global context: The politics and practices of publishing in English. Routledge.

Martins, D. S. (Ed.) (2015). Transnational writing program administration. Utah State University Press. 